\title{
BARREIRAS À IMPLANTAÇÃO DO RELATO INTEGRADO NAS INSTITUIÇÕES PÚBLICAS DE ENSINO SUPERIOR
}

\section{ARTIGO ORIGINAL}

RESENDE, Luiz Felipe Silva de ${ }^{1}$, QUELHAS, Osvaldo Luiz Gonçalves², COSTA, Stella Regina Reis da ${ }^{3}$, PEREIRA, Fernando Neves ${ }^{4}$

RESENDE, Luiz Felipe Silva de. Et al. Barreiras à implantação do relato integrado nas instituições públicas de ensino superior. Revista Científica Multidisciplinar Núcleo do Conhecimento. Ano. 06, Ed. 10, Vol. 02, pp. 27-54. Outubro 2021. ISSN: 2448-0959, Link de acesso: https://www.nucleodoconhecimento.com.br/engenharia-de-producao/relato-

integrado, $\quad$ DOI: $\quad 10.32749 /$ nucleodoconhecimento.com.br/engenharia-deproducao/relato-integrado

\section{RESUMO}

O mundo moderno é um grande consumidor de recursos naturais e, nessa preocupação, as Organizações (públicas, privadas e do terceiro setor) almejam inovação contínua na busca por um processo de gestão mais econômico e sustentável. Isso passou a ser encarado como uma ferramenta garantidora de resultados, auxiliando assim os gestores a tomarem as melhores decisões. As práticas de gestão sustentável nas IES impactam no aumento do comprometimento organizacional com a sustentabilidade. O presente artigo, tem como problemática, a necessidade de avaliar e buscar barreiras na implementação para a divulgação do Relato Integrado em Instituições de Ensino Superior no Brasil para então sugerir uma proposta de melhoria da implantação de relato integrado nestas instituições. O

\footnotetext{
${ }^{1}$ Mestrado em Sistemas de Gestão - Universidade Federal Fluminense/RJ. Pós-Graduação em Docência em Ensino Superior (2018) - Universidade Anhanguera - Uniderp - MS. Graduação em Engenharia Elétrica (2017) Centro Universitário Anhanguera de Niterói - RJ. ORCID: https://orcid.org/0000-0001-6940-7229.

2 Doutorado. ORCID: https://orcid.org/0000-0001-6816-1677.

${ }^{3}$ Doutorado. ORCID: https://orcid.org/0000-0003-4235-9890.

${ }^{4}$ Doutorado. ORCID: https://orcid.org/0000-0002-5721-6131.
}

RC: 98639

Disponível em: https://www.nucleodoconhecimento.com.br/engenharia-deproducao/relato-integrado 
objetivo desta pesquisa foi identificar as barreiras à implantação de um relato integrado conforme a literatura recomenda, propondo formas de atender às boas práticas para desenvolver uma sistemática para a implantação do Relato Integrado em Instituições de Ensino Superior públicas, conforme a IN TCU 84/2020. A metodologia utilizada foi a pesquisa bibliográfica e documental relacionadas aos eventos de gestão e sustentabilidade, como exigidos nas declarações de prestações de contas, por meio do Relato Integrado. Destacam-se como resultados a elaboração de uma sistemática contendo um diagrama de processos, um checklist para elaboração do Relato Integrado de organizações públicas, visando facilitar sua implementação, e um framework buscando a melhoria contínua desse processo de mudança e a divulgação das dificuldades encontradas na Instituição. Para que a sistemática seja utilizada por todas as instituições públicas de ensino, é necessário que seja adequada para cada realidade organizacional.

Palavras-chave: Relato Integrado, Sustentabilidade, Instituições de Ensino Superior, IES, Prestações de contas.

\section{INTRODUÇÃO}

O mundo moderno é um grande consumidor de recursos naturais e, nessa preocupação, as Organizações (públicas, privadas e do terceiro setor) almejam inovação contínua na busca por processo de gestão mais econômica e sustentável. Isso passou a ser encarado como uma ferramenta garantidora de resultados, auxiliando assim os gestores a tomarem as melhores decisões. A transparência da prestação de contas é um instrumento que tem por finalidade avaliar receitas e despesas, mas também a informação não financeira, em especial, a nível ambiental, de responsabilidade social e desenvolvimento sustentável, a fim de avaliar e dar suporte e direção a essas organizações e seus stakeholders. Ou seja, uma vez implementado, visa melhorar a qualidade e profundidade das informações apresentadas pelas organizações. 
Diante do pensar ecologicamente correto e agir buscando economia financeira, fazse necessário pensar que existem também formas de se reduzir custos, fazendo o uso do máximo de recursos renováveis e sustentáveis, em busca de uma diminuição no impacto ambiental, assim como na produção de energia limpa. O Brasil apresenta sua matriz energética com uma composição renovável. Além das hidrelétricas, esse fato o coloca em posição de destaque ao considerar a energia eólica $(7,21 \%)$ e de biomassa (8,4\%) (SANQUETTA, 2017).

Este longo caminho data de 1992, onde, no Rio de Janeiro, a Conferência das Nações Unidas, conhecida como Eco-92, foi realizada, colocando o país na vanguarda do tema. Neste mesmo período, o Ministério da Educação (MEC) organizou um workshop para discutir a educação ambiental no ensino superior (BARBIERI, 2004, p. 926).

Após vinte anos, na Conferência das Nações Unidas sobre Desenvolvimento Sustentável, mais conhecida como Rio +20 , foi estabelecido um marco fundamental para a evolução, implantação e divulgação da sustentabilidade, só que neste momento voltado para as empresas. O documento final da Conferência Rio+20, em 2012, incluiu, de forma inédita, o parágrafo 47, que apoia a adoção dos relatos integrados pelas empresas (Rio+20, 2012).

Eccles e Krzus (2011) encorajam as empresas à utilização da web no fornecimento de informações financeiras e não financeiras de forma integrada, o que, dificilmente, poderia ser alcançado em papel. Além disso, há diversas ferramentas analíticas utilizadas pela internet, a qual permite que diferentes tipos de usuários (stakeholders) da empresa façam suas próprias análises da informação financeira e não financeira disponibilizadas por ela.

Por seu turno, em 2013, o International Integrated Reporting Council (IIRC), Conselho Internacional para Relato Integrado, publicou o documento "Estrutura Internacional para Relato Integrado" (IIRC, 2013), com o objetivo de oferecer, para a comunicação corporativa, um framework para relatos corporativos que contemple 
informações financeiras e não financeiras, bem como privilegie a geração de valor das organizações ao longo do tempo. A Estrutura foca no setor privado e visa melhorar a qualidade da informação disponível aos provedores de capital financeiro, promover uma abordagem mais coesa e eficiente, melhorar a responsabilidade pela gestão dos capitais à disposição, fomentando suas interdependências, e apoio à integração do pensamento, da tomada de decisão e das ações que focam na geração de valor no curto, médio e longo prazos.

A partir de 2018, por determinação do Tribunal de Contas da União (TCU), através da DN TCU 170/2018, que passou a exigir a preparação e apresentação de relatório integrado por todos os órgãos e entidades da administração direta e indireta, a qual orientava às instituições de ensino a elaborarem documentos mais objetivos e compactos.

De acordo com Silva e Lia (2019), entende-se que grande parte dos trabalhos direcionadas para a análise da sustentabilidade nas IES não contemplam as dimensões sociais, ambientais e econômicas. Os trabalhos internacionais não apresentam aderência e aplicabilidade para a realidade das universidades brasileiras. Ressalta-se que, conforme destacado em outras análises, como Cole (2003), Drahein (2016), Lozano (2006), Oliveira (2015) e Shriberg (2002), as dimensões aplicadas à sustentabilidade geralmente se referem à sustentabilidade ambiental, por vezes, deixando de aplicar uma análise mais completa, voltada também para as dimensões social e econômica.

Neste contexto, mostra-se a necessidade da construção de uma sistemática abordando mais sobre esse tema de forma pensada e incorporada pelas Instituições de Ensino Superior públicas no Brasil, buscando sintetizar neste trabalho informações que busquem mitigar as dificuldades e barreiras de implementação do Relato Integrado nessas instituições.

Segundo Gottardo (2002), o desenvolvimento econômico deve ser realizado por meio de estruturas capazes de proporcionar distribuição de renda mais equitativa, 
além de mais controles do Estado sobre as diferentes formas de atribuição de uso dos recursos naturais. Por isso, não cabe enxergá-lo de forma isolada, pois assim permitiria apenas uma abordagem quantitativa interpretada por meio de indicadores econômicos, como o Produto Interno Bruto (PIB), a taxa de investimentos, a renda per capta, dentre outros.

Segundo Cerqueira (2017), a questão da sustentabilidade no contexto do ensino superior é, em certa medida, um tema recente. Uma vez que mais de 600 universidades em todo o mundo se comprometeram com a sustentabilidade, assinando acordos e convenções internacionais como a Carta de Bolonha, a Declaração de Halifax, a Declaração de Talloires e a Carta Copernicus para o Desenvolvimento Sustentável, tornando-se campo de pesquisa emergente. Mais recentemente, a Agenda 2030, acordada pela Assembleia Geral da ONU em novembro de 2015 e os Objetivos de Desenvolvimento Sustentável (ODS) significam que as instituições de ensino superior devem, mais do que nunca, se engajar na implementação do desenvolvimento sustentável em todas as áreas temáticas.

As mudanças na economia, a globalização, a diversidade dos profissionais e a tecnologia, criaram novas demandas para as universidades e impulsionaram a inclusão da sustentabilidade nos seus objetivos estratégicos (STONE; DEADRICK, 2015; ULRICH; DULEBOHN, 2015). A valorização do equilíbrio entre as perspectivas da integridade ambiental, da prosperidade econômica e da equidade social (REIS, 2017), fez emergir um novo paradigma: a gestão sustentável de Instituições de Ensino Superior (IES). Essa abordagem reconhece resultados da gestão das organizações mais amplos, incluindo aspectos humanos e sociais nos processos gerenciais.

Conforme Ramísio (2019), as IES tomam o seu papel nos processos para uma mudança social, colaborando para a mudança de novas gerações de profissionais e incentivando a sociedade a compreender a importância de desenvolver ações mais sustentáveis para a manutenção da qualidade de vida. Para Góes (2015), os princípios de sustentabilidade devem estar inseridos nos processos de gestão e 
governança das Instituições de Ensino Superior (IES), bem como em suas funções precípuas que são: educação, pesquisa e extensão. Com isso, pode-se dizer que as Instituições de Ensino Superior (IES) possuem um papel importante no desenvolvimento sustentável e elas próprias devem ser modelos de sustentabilidade para a sociedade, conforme Fouto (2002). Além disso, são responsáveis pelo fomento de pesquisas em áreas correlatas, dessa forma, necessitam estar alinhadas com as questões globais de maneira a implementar em sua política ações voltadas ao meio ambiente, que possam convergir os interesses de sua comunidade acadêmica e da sociedade.

Logo, se faz necessário avaliar a necessidade de buscar barreiras na implementação para a divulgação do Relato Integrado em Instituições de Ensino Superior no Brasil, para então sugerir uma proposta de melhoria da implantação de relato integrado nestas instituições. Neste contexto, qual é a sistemática para a implantação do Relato Integrado em Instituições de Ensino Superior públicas?

Esta é uma questão preponderante no cenário global e precisa de um correto alinhamento com políticas públicas e com as novas tecnologias presentes no mercado, sejam elas desenvolvidas no âmbito acadêmico ou por incorporação de boas práticas.

O tema abordado é relevante para toda sociedade humana, pois convida a todos a buscarem apoio na humanidade e na responsabilidade para mantermos o planeta vivo. Os documentos firmam, de forma global, conceitos de meio ambiente inseridos na relação do homem socioambiental.

E Por fim, o objetivo central da pesquisa foi responder à seguinte pergunta "É possível identificar as barreiras à implantação de um relato integrado conforme a literatura recomenda, propondo formas de atender às boas práticas para desenvolver uma sistemática para a implantação do Relato Integrado em Instituições de Ensino Superior públicas conforme a IN TCU 84/2020?". 


\section{RELATO INTEGRADO}

A Lei no 13.303/2016, que é conhecida como a lei das Estatais, foi promulgada em 30 de junho de 2016, essa lei passou a exigir das empresas públicas e das sociedades de economia mista a elaboração do relatório integrado. No artigo 8º, item IX: fala sobre a necessidade da divulgação anual de relatório integrado ou de sustentabilidade.

Após a nova regulamentação geral de prestação de contas estabelecida na Instrução Normativa (IN)-TCU84/2020 e a DN TCU 179 de 20 de novembro de 2019, que versa também sobre o RG 2020, aconteceram mudanças expressivas para os procedimentos referentes à obrigação dos gestores públicos de prestar contas. Todavia, no que tange ao relatório de gestão, essa Instrução Normativa preservou a adoção de estrutura de conteúdo e de diretrizes que têm sido implementadas desde as contas do exercício de 2018, já que esse modelo é fortemente alinhado com o modelo de Relato Integrado (International Integrated Reporting Council - IIRC) (TCU, 2020).

Em 2013, foi publicada a primeira versão da Estrutura Internacional para Relato Integrado. Tal estrutura contém os princípios básicos, conceitos fundamentais e elementos de conteúdo para orientar a preparação e elaboração do Relato Integrado de modo coerente e coeso, entre os diversos relatórios exigidos e divulgados pelas empresas (Carvalho; Kassai, 2014).

Segundo a Comissão Brasileira de Acompanhamento do Relato Integrado (CBARI, 2013) os capitais de uma organização são divididos em seis e podem ser definidos como:

a) capital financeiro: está disponível a uma organização para ser utilizado na produção de bens ou na prestação de serviços;

b) capital manufaturado: objetos físicos manufaturados disponíveis a uma organização para uso na produção de bens ou serviços;

c) capital intelectual: intangíveis organizacionais baseados em conhecimento;

RC: 98639

Disponível em: https://www.nucleodoconhecimento.com.br/engenharia-deproducao/relato-integrado 
d) capital humano: tratam se das competências, habilidades e experiência das pessoas e suas motivações para inovar;

e) capital social e de relacionamento: relacionamentos internos e entre os stakeholders; a capacidade de compartilhar informações para melhorar o bem-estar, seja individual e coletivo;

f) capital natural: todos os recursos e processos renováveis e não renováveis que fornecem bens ou serviços que apoiam as prosperidades passada, presente e futura de uma organização.

$\mathrm{Na}$ Estrutura Internacional, os capitais são classificados em 6 tipos: financeiro, manufaturado, intelectual, humano, social e de relacionamento, e natural. Eles são independentes entre si, mas interagem e estão relacionados à geração de valor ao longo do tempo (IIRC, 2014). O Quadro 1 apresenta cada capital destacado na estrutura internacional de Relato Integrado. 
Quadro 1 - Capitais do Relato Integrado

\begin{tabular}{|c|c|}
\hline Tipo de Capital & Descrição \\
\hline Capital Financeiro & $\begin{array}{l}\text { Recursos disponiveis para o uso de produção de } \\
\text { bens ou prestação de serviços, podendo ser obtido } \\
\text { por diversas fontes como, por exemplo, empréstimos } \\
\text { e capital de subvenções ou gerado por meio de } \\
\text { operações ou investimentos. }\end{array}$ \\
\hline Capital Manufaturado & $\begin{array}{l}\text { Objetos fisicos disponíveis na organização para o } \\
\text { uso na produção de bens e serviços, como, por } \\
\text { exemplo, edificios, equipamentos e infraestrutura. }\end{array}$ \\
\hline Capital Intelectual & $\begin{array}{l}\text { Intangiveis que criam vantagem competitiva, } \\
\text { englobando propriedades intelectuais, como: } \\
\text { patentes, direitos autorais, software, sistemas de } \\
\text { informação e outros, centra-se em questões voltadas } \\
\text { para o futuro da organização. }\end{array}$ \\
\hline Capital Humano & $\begin{array}{l}\text { Relações de competência e experiência das pessoas, } \\
\text { envolvendo as habilidades e motivações para a } \\
\text { inovação, incluindo o alinhamento e apoio para a } \\
\text { governança corporativa, a gestão de risco e valores } \\
\text { éticos, a capacidade de desenvolver e implantar } \\
\text { estratégia corporativa e a lealdade e motivação para } \\
\text { liderar, gerenciar e capacitar equipes e qualificar } \\
\text { processos, produtos e serviços. }\end{array}$ \\
\hline $\begin{array}{l}\text { Capital Social e de } \\
\text { Relacionamento }\end{array}$ & $\begin{array}{l}\text { Relações e instituições estabelecidas com as } \\
\text { comunidades, partes relacionadas e outros grupos } \\
\text { para melhorar o bem-estar individual e coletivo, e se } \\
\text { revela em alguns aspectos como valores e } \\
\text { comportamentos comuns e uma licença social para a } \\
\text { organização exercer sua atividade operacional. }\end{array}$ \\
\hline Capital Natural & $\begin{array}{l}\text { Ações ambientais renováveis e não renováveis que } \\
\text { fornecem um fluxo de produtos e serviços, sendo } \\
\text { que interfere positivamente ou negativamente sobre } \\
\text { o capital natural, que inclui água, terra, minerais, } \\
\text { florestas, biodiversidade e outros. }\end{array}$ \\
\hline
\end{tabular}

Fonte: IIRC $(2013,2014)$.

A sociedade civil pressiona as organizações a divulgarem informações que, posteriormente, são utilizadas para promulgarem um processo de compromisso que leva à transformação (ECCLES e SPIESSHOFER, 2017).

RC: 98639

Disponível em: https://www.nucleodoconhecimento.com.br/engenharia-deproducao/relato-integrado 
O relato integrado é um documento que visa sintetizar informações corporativas de maneira a dar maior credibilidade ao mercado ou a quem se destina tal documento. O relato reúne informações de diferentes áreas, as quais convergem em um único resultado, assim permitindo que usuários possam melhor avaliar todas as núncias da abordagem.

Via de regra, este documento tem papel preponderante na tomada de decisão, pois é condição fundamental para que organizações possam prover investimento, aquisições, ampliações, ou seja, gerar valor ao seu negócio, retendo investimento e ampliando a participação de agente potenciais.

Sua estrutura está pautada em requisitos básicos, no entanto, estes são mutáveis a depender a quem se destina o documento; logo, algumas circunstâncias particulares podem ser contempladas, a depender do tipo de indicador utilizado, método de mensuração e divulgação de informações.

Desta forma, o Relato Integrado visa explicar os recursos que destinam, também busca sintetizar como se dá a relação das organizações com o ambiente externo e suas perspectivas de geração de valor no curto, médio e longo prazos.

Os princípios básicos do relatório integrado são (IIRC, 2013):
a) foco estratégico;
b) alinhamento com as tecnologias;
c) relações estreitas com as partes interessadas;
d) objetividade em seu conteúdo;
e) concisão;
f) confiabilidade e completude;
g) coerência e comparabilidade. 
Percebe-se que os princípios são básicos, no entanto, a complexidade inserida neste contexto que precisa ser atacada no seu conteúdo, assim atendendo os parâmetros basilares do documento. Estes elementos são interligados e precisam interagir entre eles a somar informações. Logo, podemos destacar (IIRC, 2013):

a) visão organizacional e do ambiente externo;

b) governança (compliance);

c) modelo de negócios (Canvas);

d) riscos e oportunidades (análise SWOT);

e) estratégia e alocação de recursos;

f) análise de desempenho;

g) projeção de cenários.

O relato integrado vai além do cumprimento de requisitos obrigatórios, mas ele materializa um conjunto de aspectos, na atual conjuntura, que chancela as organizações a capacidade de mais bem tomadas de decisão, suportadas por informações fidedignas e concisas, que passam desde aspetos financeiros, a manufatura, gestão de pessoas, relacionamento com a sociedade, além de sua interação com o meio ambiente (IIRC, 2013).

Isto remete à criação de valor que não está somente relacionado com o capital financeiro, mas na redução ou preservação dos capitais outros, o que significa que a criação de valor não é apenas recurso convertido em moeda às partes interessadas, mas transpõe parâmetros, até pouco tempo atrás, pouco explorados pelas organizações.

Neste sentido, a gestão de risco é de suma importância, "pois coloca todo um planejamento a perder, uma vez que se deixa de lado a análise de aspectos externos à organização", conforme documento retirado do site da TCU. Os fatores externos podem influenciar de forma direta ou indireta a organização, podendo 
incluir como exemplo o ambiente regulatório, condições econômicas, mudanças tecnológicas, temas da sociedade e desafios ambientais (TCU, 2020).

Assim, as organizações precisam estar atentas aos fatores conjunturais deste ambiente externo em seu processo de implementação e desenvolvimento (PEREIRA, 2016):
a) Política interna e externa;
b) mercado consumidor;
c) internet das coisas;
d) logística;
e) recursos naturais;
f) mudanças climáticas;
g) leis vigentes;
h) acordos comerciais;
i) propriedade intelectual;
j) saúde.

Alguns elementos básicos do relato integrado merecem maior aprofundamento por ser difícil de serem implantados em instituições de ensino.

\section{METODOLOGIA}

A pesquisa incialmente assume um caráter de cunho exploratório sendo realizado um levantamento bibliográfico e documental via Internet, livros didáticos, dissertações, teses, trabalhos publicados e revistas científicas nacionais e internacionais (GIL, 2008).

Para o desenvolvimento do artigo foi realizada as aplicações de práticas voltadas à elaboração do Relato Integrado e identificadas as ações em instituições públicas, 
bem como um mapeamento das características documentais em cumprimento aos requisitos legais do TCU, sobre o qual foi elaborado o diagrama de processos e checklist, de modo que a partir destes estudos e análise crítica dos dados levantados, subsidia a proposta de intervenção do trabalho. Desta maneira está sendo proposto um processo de levantamento de barreiras quanto aos cumprimentos de parâmetros do Relato Integrado, propostos por lei através do TCU, assim como o documento "Relatório de Gestão: guia para elaboração na forma de relato integrado: evolução da prestação de contas (2020)".

Através dos levantamentos bibliográficos e documentais sobre o atual estado da arte no que tange à adoção de modelos de relatórios técnicos voltados aos cumprimentos dos requisitos do Relato Integrado pelas IES públicas, foi produzido e aplicado checklist, a fim de obter uma análise prévia desta IES, para que se possa observar os reflexos da ferramenta estudada no cotidiano da organização nos vários aspectos levantados no referencial teórico. Desta forma, na Figura 1 é apresentado um desenho do método. 
Figura 1 - Desenho da pesquisa, seus componentes e métodos
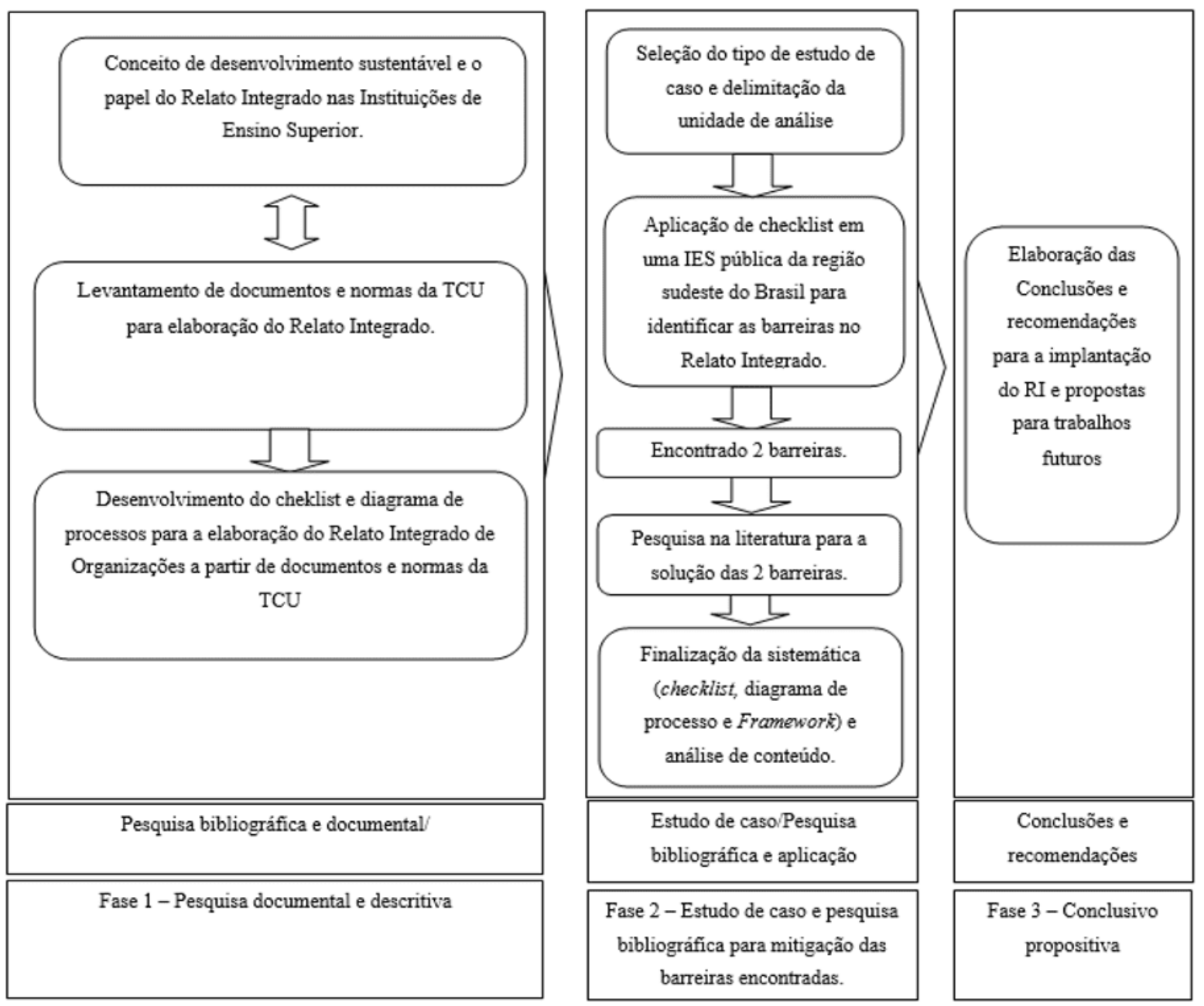

Fonte: Elaborado pelo autor (2021).

O desenho do estudo mostra a sequência lógica de cada estágio, seguindo os métodos utilizados no trabalho de investigação e no trabalho de pesquisa, como descrito abaixo. A pesquisa bibliográfica e documental na primeira fase, visa propor trabalhos conceituais, documentos relacionados aos eventos de gestão e sustentabilidade, como exigidos nas declarações de prestações de contas, através do Relato Integrado, para confirmar o objetivo geral da pesquisa. 
A pesquisa documental confirmou a definição do modelo conceitual para montagem de um diagrama de processos para elaboração do Relatório Integrado, com base nas orientações do TCU, com esse diagrama de processos foi elaborado o checklist.

Em seguida foi realizada a seleção do estudo de caso com a aplicação do checklist, submetido ao Relatório Integrado de uma Instituição de Ensino Superior pública na região sudeste do Brasil, o qual encontrou 2 barreiras neste Relatório Integrado. A partir dessas barreiras encontradas, foi possível concluir os objetivos específicos. $O$ primeiro objetivo consistiu em identificar na literatura as recomendações sobre elaboração de relato integrado em instituições públicas, e buscar as barreiras encontradas entre o proposto pelo TCU e o relatório de uma Instituição de Ensino Superior da região Sudeste do Brasil; o segundo objetivo específico foi desenvolver, dentro da construção do referencial teórico, a identificação da solução dessas barreiras, a avaliação do material produzido e elaborar um framework sobre as boas práticas recomendadas pela literatura para a implantação e o conteúdo de um relato integrado em instituição pública.

\section{RESULTADOS E DISCUSSÃO}

Com base na análise realizada no documento do TCU, Relatório de gestão: guia para elaboração na forma de relato integrado: evolução da prestação de contas (2020) foi elaborado um diagrama para avaliação de relatórios integrados conforme apresentado na Figura 2 a seguir. 
Figura 2 - Diagrama de estrutura e conteúdo para elaboração do relatório (continua).

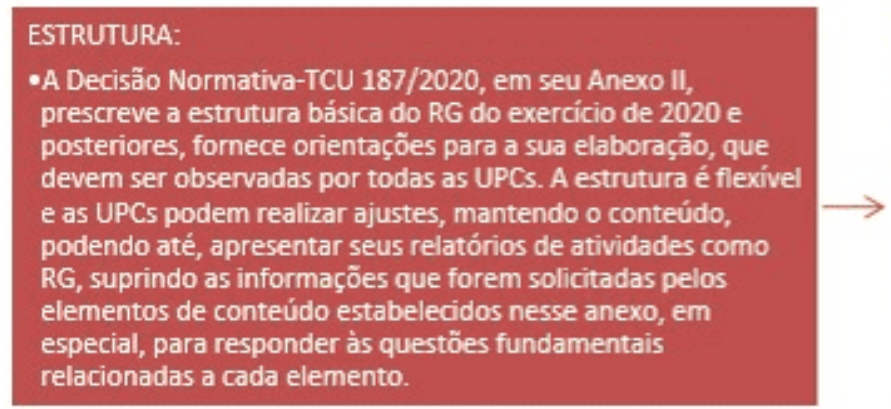

VISÃO GERAL ORGANIZACIONAL E AMBIENTE EXTERNO:

-Precisa responder o que é a organização, o que faz e quais são as circunstâncias em que atua;

•Qual o modelo de negócios da organização;

- Como a organização determina os temas a serem incluídos no relatório de gestäo e como estes ternas são quantificados ou avaliados;

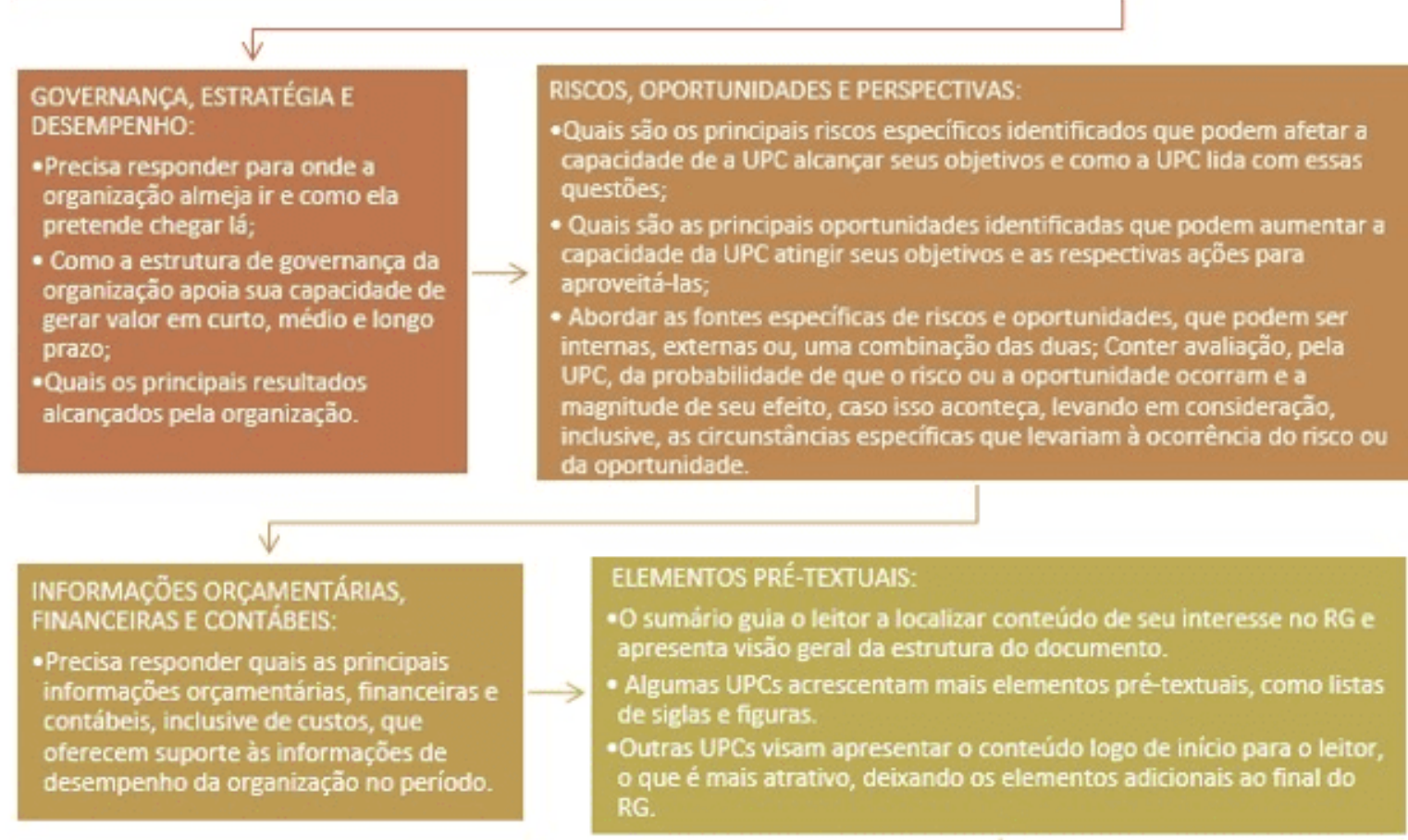

\section{MENSAGEM DO DIRIGENTE:}

- Apresentaçăo concisa do relatório de gestão, elaborada, de preferência pelo dirigente máxime responsável pela gestăo no exercicio de referência ou. em caso de impossibilidade, pelo dirigente máximo no exercício do cargo na data limite para entrega das contas, abordando, especialmente, os pontos da Bestäo do exercicio que merecem destaque, tais como um resumo dos principais resultados alcancados frente aos objetivos estratégicos e às prioridades da gestäo, detalhados no corpo do relatório.

- A mensagem do dirigente deve conter a importância de sua responsabilidade por assegurar a integridade do RG.

\section{VISÃO GERAL ORGANIZACIONAL E} AMBIENTE EXTERNO:

- Deve apresentar informações que identificam a UPC, sua estrutura organizacional e de governança, 0 ambiente externo em que atua e $c$ modelo de negócios

- Deve responder. O que é a organizaçáo, o que faz equais säo as circunstâncias em que atua.

-Qual o modelo de negócios;

- Como a organizaçăo determina os temas a serem incluidos no relatório integrado e como säo quantificados ou avaliados.

RC: 98639

Disponível em: https://www.nucleodoconhecimento.com.br/engenharia-deproducao/relato-integrado 
Figura 2 - Diagrama de estrutura e conteúdo para elaboração do relatório (continua)
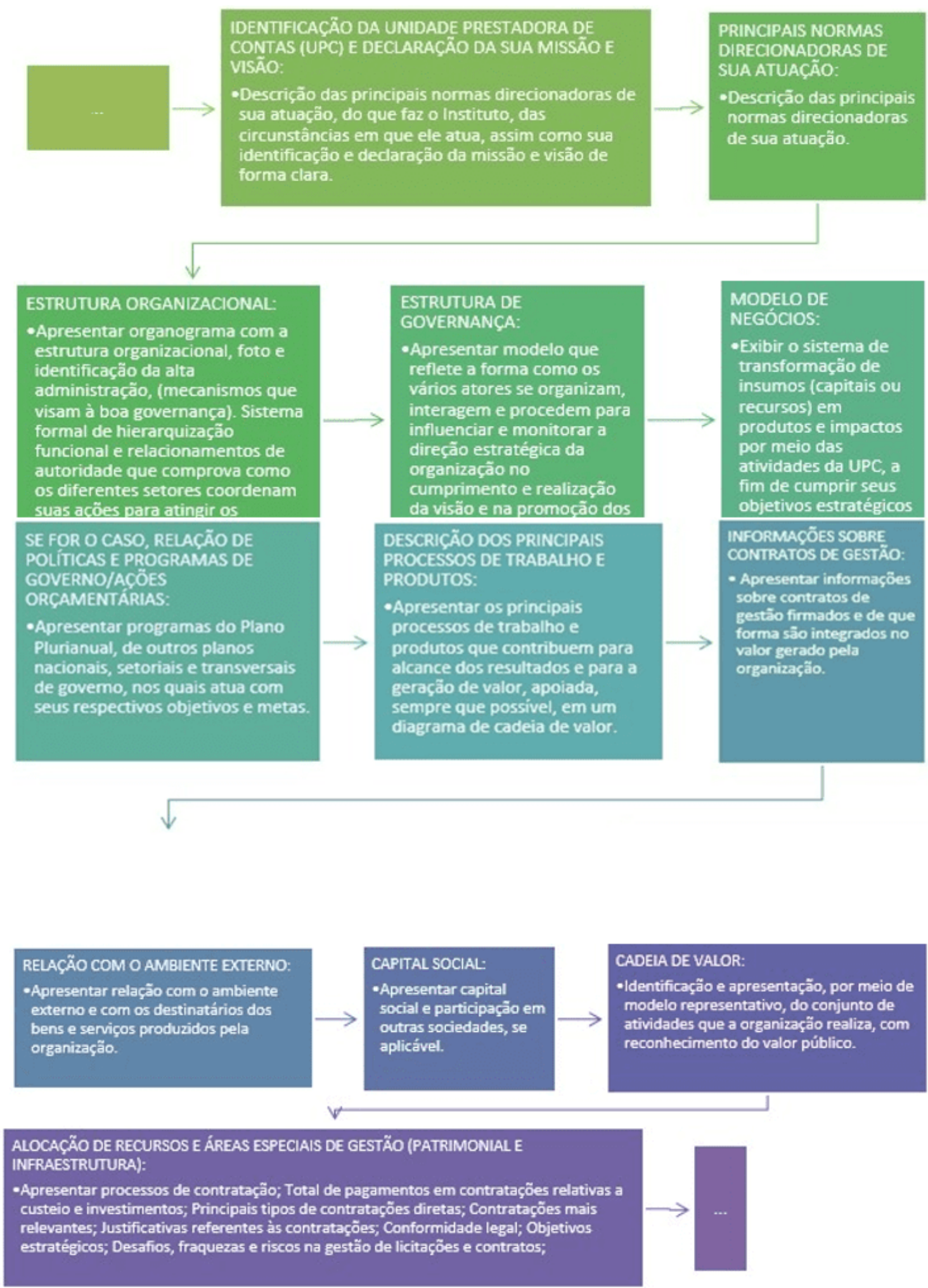

RC: 98639

Disponível em: https://www.nucleodoconhecimento.com.br/engenharia-deproducao/relato-integrado 
Figura 2 - Diagrama de estrutura e conteúdo para elaboração do relatório (conclusão)

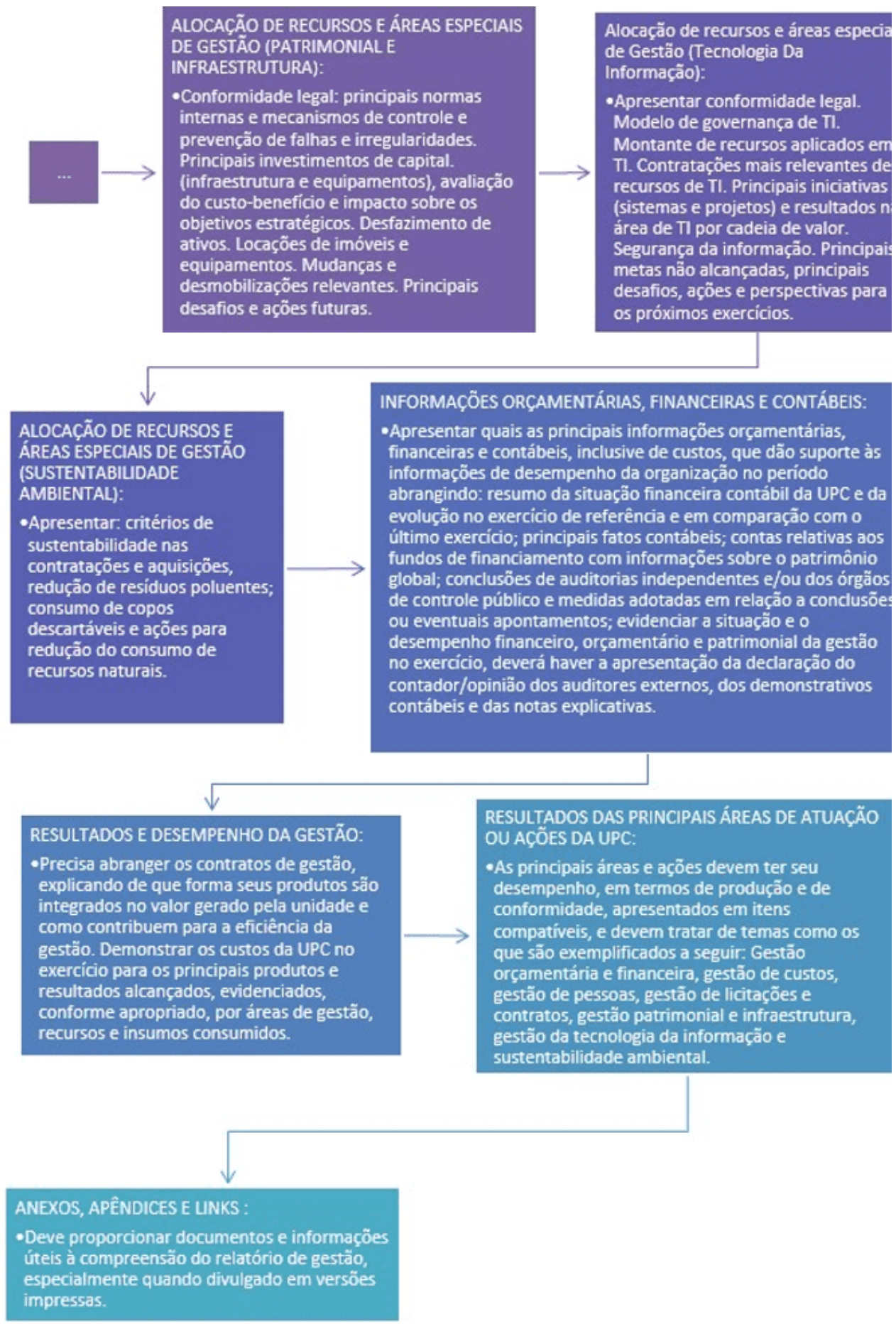

Fonte: Elaborado pelo autor (2021).

RC: 98639

Disponível em: https://www.nucleodoconhecimento.com.br/engenharia-deproducao/relato-integrado 
Após produzir o diagrama de processos de elaboração do Relato Integrado, a partir do documento "Relatório de gestão: guia para elaboração na forma de relato integrado, evolução da prestação de contas (2020)", foi possível criar um checklist de avaliação do Relatório da instituição estudada, o apresentado no Quadro 1 a seguir:

Quadro 1- Checklist de avaliação do Relato Integrado (continua)

\begin{tabular}{|c|c|c|c|c|}
\hline \multicolumn{5}{|c|}{ CHECKLIST PARA AVALIAÇÃO DO RELATO INTEGRADO } \\
\hline \multicolumn{5}{|c|}{ (Luiz Felipe Silva de Resende 03/2020) } \\
\hline \multicolumn{5}{|c|}{$\begin{array}{l}\text { Referências: orientações disponibilizadas na página de contas do portal do TCU: Guia para Elaboração na Forma } \\
\text { de Relato Integrado - } 2020 \text {. }\end{array}$} \\
\hline \multicolumn{5}{|c|}{ https://portal.tcu.gov.br/lumis/portal/file/fileDownload.jsp?fileId=8A81881F759554350175DC308B5211EB } \\
\hline LEGENDA: & \multicolumn{4}{|c|}{$\begin{array}{l}\text { RG: RELATÓRIO DE GESTÃO / UPC: UNIDADE DE PRESTADORA DE CONTAS / RI: } \\
\text { RELATO INTEGRADO }\end{array}$} \\
\hline TÓPICOS & SUBTÓPICOS & CONTEÚDO & $\begin{array}{l}\text { RG } \\
\text { ATENDE } \\
(\mathrm{S} / \mathrm{N})\end{array}$ & $\begin{array}{l}\text { RG não } \\
\text { atende e } \\
\text { deve ser } \\
\text { ajustado. } \\
\text { Evidenciar } \\
\text { barreiras } \\
\text { encontradas } \\
\text { na } \\
\text { informação } \\
\text { do RG }\end{array}$ \\
\hline \multirow{3}{*}{$\begin{array}{l}\text { Estrutura e } \\
\text { conteúdo } \\
\text { para } \\
\text { elaboração } \\
\text { do Relatório }\end{array}$} & Estrutura: & $\begin{array}{l}\text { A Decisão Normativa-TCU 187/2020, em seu } \\
\text { Anexo II, prescreve a estrutura básica do RG } \\
\text { do exercício de } 2020 \text { e posteriores, fornece } \\
\text { orientações para a sua elaboração, que devem } \\
\text { ser observadas por todas as UPCs. A estrutura é } \\
\text { flexivel e as UPCs podem realizar ajustes, } \\
\text { mantendo o conteúdo, ou, até mesmo, } \\
\text { apresentar seus relatórios de atividades como } \\
\text { RG, suprindo as informações que forem } \\
\text { solicitadas pelos elementos de conteúdo } \\
\text { estabelecidos nesse anexo, em especial, para } \\
\text { responder às perguntas fundamentais } \\
\text { relacionadas a cada elemento. }\end{array}$ & $\mathrm{S}$ & \\
\hline & $\begin{array}{l}\text { Visão geral } \\
\text { organizacional } \\
\text { e ambiente externo }\end{array}$ & $\begin{array}{l}\text { Precisa responder o que é a organização, o que } \\
\text { faz e quais rão ras a } \\
\text { circunstâncias em que atua. Qual o modelo de } \\
\text { negócios da } \\
\text { Como a organização determina os temas a } \\
\text { serem incluídos no relatório de gestão e como } \\
\text { estes temas são quantificados ou avaliados. }\end{array}$ & S & \\
\hline & $\begin{array}{l}\text { Governança, estratégia e } \\
\text { desempenho }\end{array}$ & $\begin{array}{l}\text { Precisa responder para onde a organização } \\
\text { almeja ir e como ela pretende chegar lá. Como } \\
\text { a estrutura de governança da organização apoia } \\
\text { sua capacidade de gerar valor em curto, médio } \\
\text { e longo prazo. Quais os principais resultados } \\
\text { alcançados pela organização. }\end{array}$ & S & \\
\hline
\end{tabular}

RC: 98639

Disponível em: https://www.nucleodoconhecimento.com.br/engenharia-deproducao/relato-integrado 


\section{Quadro 2 - Checklist de avaliação do Relato Integrado (continua)}

\begin{tabular}{|c|c|c|c|c|}
\hline \multirow{3}{*}{$\begin{array}{l}\text { Estrutura } \\
\text { conteúdo } \\
\text { para } \\
\text { elaboração } \\
\text { do } \\
\text { Relatório }\end{array}$} & $\begin{array}{l}\text { Riscos, oportunidades } \\
\text { eperspectivas }\end{array}$ & $\begin{array}{l}\text { Quais são os principais riscos } \\
\text { específicos identificados, que podem } \\
\text { afetar a capacidade de a UPC alcançar } \\
\text { seus objetivos e como a UPC lida com } \\
\text { essas questões. Quais são as principais } \\
\text { oportunidades identificadas que podem } \\
\text { aumentar a capacidade de a UPC atingir } \\
\text { seus objetivos e as respectivas ações } \\
\text { para aproveitá-las. Abordar as fontes } \\
\text { específicas de riscos e oportunidades, } \\
\text { que podem ser internas, externas ou, } \\
\text { normalmente, uma combinação das } \\
\text { duas. Conter avaliação, pela UPC, da } \\
\text { probabilidade de que o risco ou a } \\
\text { oportunidade ocorram e a magnitude de } \\
\text { seu efeito, caso isso aconteça, levando } \\
\text { em consideração, inclusive, as } \\
\text { circunstâncias específicas que levariam } \\
\text { à ocorrência do risco ou da } \\
\text { oportunidade. }\end{array}$ & $\mathrm{S}$ & \\
\hline & $\begin{array}{l}\text { Informações } \\
\text { orçamentárias, } \\
\text { financeiras e contábeis }\end{array}$ & $\begin{array}{l}\text { Precisa responder quais as principais } \\
\text { informações orçamentárias, financeiras } \\
\text { e contábeis, inclusive de custos, que } \\
\text { oferecem suporte às informações de } \\
\text { desempenho da organização no período. }\end{array}$ & $\mathrm{N}$ & $\begin{array}{l}\text { No relatório consta } \\
\text { declaração do } \\
\text { contador informando } \\
\text { justificativas para } \\
\text { permanência de } \\
\text { restrições contábeis no } \\
\text { encerramento do } \\
\text { exercício de } 2019 \text {. (A } \\
\text { barreira encontrada foi } \\
\text { a falta de } \\
\text { contador/profissional } \\
\text { exclusivo para } \\
\text { conformidade } \\
\text { contábil) }\end{array}$ \\
\hline & Elementos pré-textuais & $\begin{array}{l}\text { O sumário guia o leitor a localizar } \\
\text { conteúdo de seu interesse no RG e } \\
\text { apresenta visão geral da estrutura do } \\
\text { documento. Algumas UPCs } \\
\text { acrescentam mais elementos pré- } \\
\text { textuais, como listas de siglas e figuras. } \\
\text { Outras UPCs visam apresentar o } \\
\text { conteúdo logo de início para o leitor, o } \\
\text { que é mais atrativo, deixando os } \\
\text { elementos adicionais ao final do RG. }\end{array}$ & $\mathrm{S}$ & \\
\hline
\end{tabular}




\section{Quadro 2 - Checklist de avaliação do Relato Integrado (continua)}

\begin{tabular}{|c|c|c|c|}
\hline \multirow{5}{*}{$\begin{array}{l}\text { Estrutura e } \\
\text { conteúdo } \\
\text { para } \\
\text { elaboração } \\
\text { do } \\
\text { Relatório }\end{array}$} & $\begin{array}{l}\text { Mensagem } \\
\text { dirigente }\end{array}$ & $\begin{array}{l}\text { Apresentação concisa do relatório de gestão, } \\
\text { elaborada, de preferência, pelo dirigente } \\
\text { máximo responsável pela gestão no exercício } \\
\text { de referência ou, em caso de impossibilidade, } \\
\text { pelo dirigente máximo no exercício do cargo } \\
\text { na data limite para a entrega das contas, } \\
\text { abordando, especialmente, os pontos da gestão } \\
\text { do exercício que merecem destaque, tais como } \\
\text { um resumo dos principais resultados } \\
\text { alcançados frente aos objetivos estratégicos e } \\
\text { às prioridades da gestão, detalhados no corpo } \\
\text { do relatório. A mensagem do dirigente deve } \\
\text { conter a importância de sua responsabilidade } \\
\text { por assegurar a integridade do RG. }\end{array}$ & $S$ \\
\hline & $\begin{array}{l}\text { Visão geral } \\
\text { organizacional e } \\
\text { ambiente externo }\end{array}$ & $\begin{array}{l}\text { Deve apresentar informações que identificam a } \\
\text { UPC, sua estrutura organizacional e de } \\
\text { governança, o ambiente externo em que atua e } \\
\text { o modelo de negócios. Deve responder o que é } \\
\text { a organização, o que faz e quais são as } \\
\text { circunstâncias em que atua. Qual o modelo de } \\
\text { negócios. Como a organização determina os } \\
\text { temas a serem incluídos no relatório integrado } \\
\text { e como são quantificados ou avaliados. }\end{array}$ & $S$ \\
\hline & $\begin{array}{l}\text { Identificação da } \\
\text { Unidade Prestadora } \\
\text { de Contas (UPC) e } \\
\text { declaração da sua } \\
\text { missão e visão }\end{array}$ & $\begin{array}{l}\text { Descrição das principais normas direcionadas a } \\
\text { sua atuação, do que faz o Instituto, das } \\
\text { circunstâncias em que ele atua, assim como sua } \\
\text { identificação e declaração da missão e visão de } \\
\text { forma clara. }\end{array}$ & $S$ \\
\hline & $\begin{array}{l}\text { Principais normas } \\
\text { direcionadoras de } \\
\text { sua atuação }\end{array}$ & $\begin{array}{l}\text { Descrição das principais normas } \\
\text { direcionadoras de sua atuação. }\end{array}$ & $S$ \\
\hline & $\begin{array}{l}\text { Estrutura } \\
\text { organizacional }\end{array}$ & $\begin{array}{l}\text { Apresentar organograma com a estrutura } \\
\text { organizacional, foto e identificação da alta } \\
\text { administração, (mecanismos que visam à boa } \\
\text { governança). Sistema formal de hierarquização } \\
\text { funcional e relacionamentos de autoridade que } \\
\text { comprovam como os diferentes setores } \\
\text { coordenam suas ações para atingir os objetivos } \\
\text { organizacionais. }\end{array}$ & $S$ \\
\hline
\end{tabular}


Quadro 2 - Checklist de avaliação do Relato Integrado (continua)

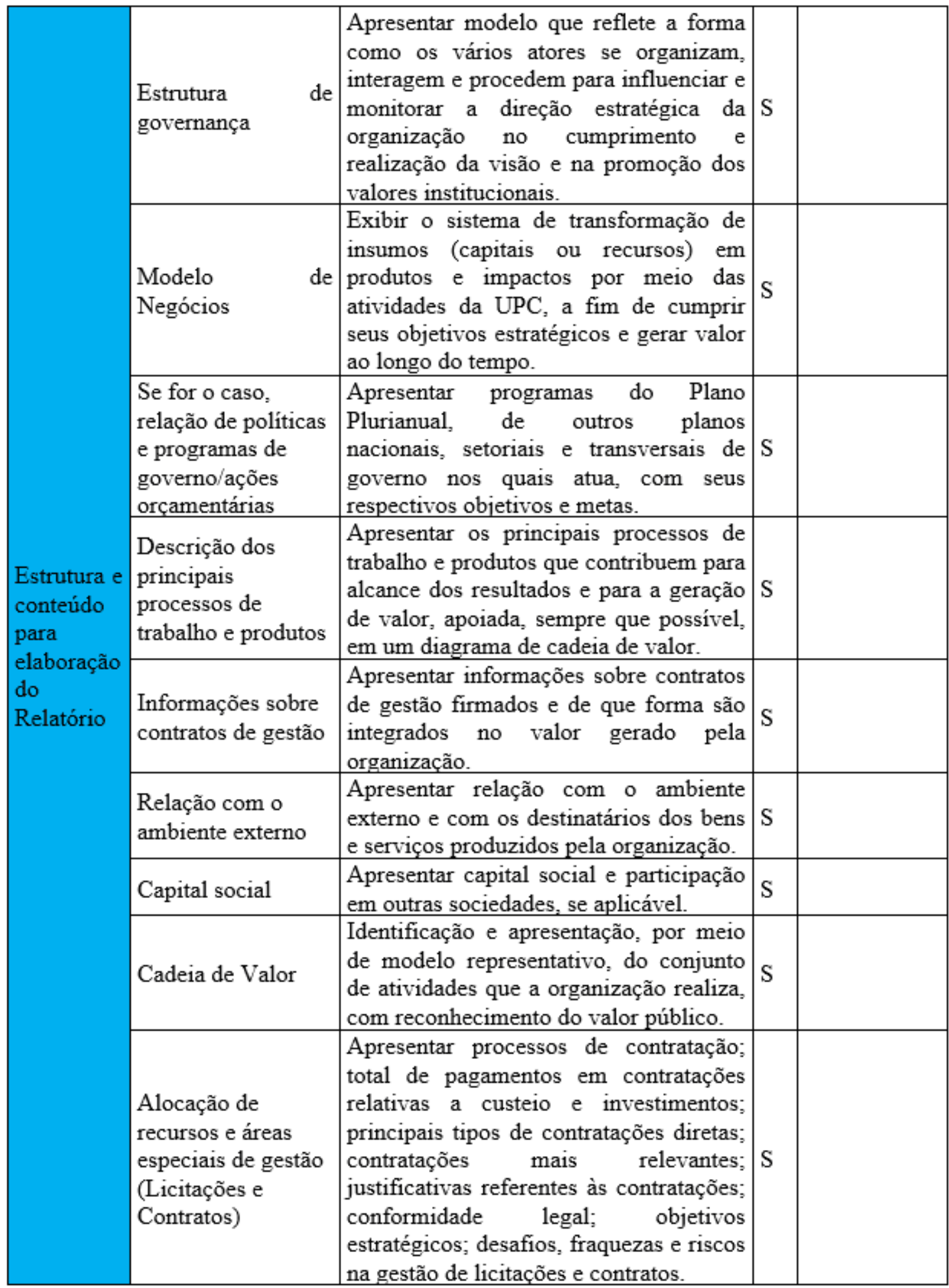


Quadro 2 - Checklist de avaliação do Relato Integrado (continua)

\begin{tabular}{|c|c|c|c|}
\hline \multirow{2}{*}{$\begin{array}{l}\text { Estrutura e } \\
\text { conteúdo } \\
\text { para } \\
\text { elaboração } \\
\text { do } \\
\text { Relatório }\end{array}$} & $\begin{array}{l}\text { Alocação de } \\
\text { recursos e áreas } \\
\text { especiais de gestão } \\
\text { (Patrimonial e } \\
\text { Infraestrutura) }\end{array}$ & 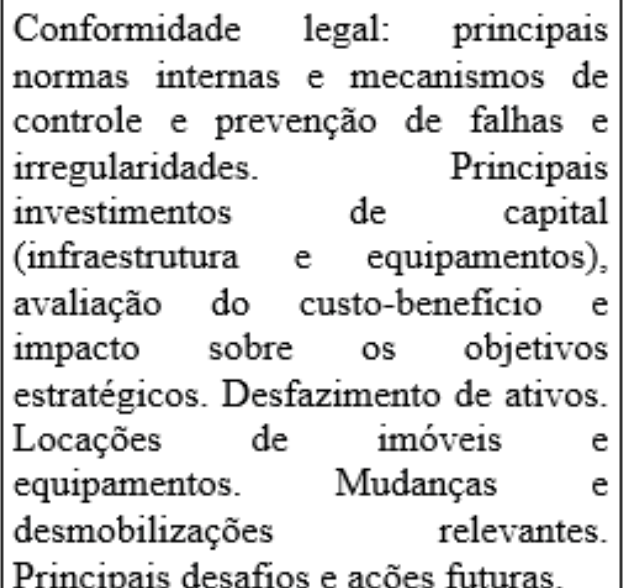 & S \\
\hline & $\begin{array}{l}\text { Alocação de } \\
\text { recursos e áreas } \\
\text { especiais de gestão } \\
\text { (Tecnologia Da } \\
\text { Informação) }\end{array}$ & $\begin{array}{l}\text { Apresentar conformidade legal. } \\
\text { Modelo de governança de TI. } \\
\text { Montante de recursos aplicados em } \\
\text { TI. Contratações mais relevantes de } \\
\text { recursos de TI. Principais iniciativas } \\
\text { (sistemas e projetos) e resultados na } \\
\text { área de TI por cadeia de valor. } \\
\text { Segurança da informação. Principais } \\
\text { metas não alcançadas, principais } \\
\text { desafios, ações e perspectivas para os } \\
\text { próximos exercícios. }\end{array}$ & $S$ \\
\hline
\end{tabular}

RC: 98639

Disponível em: https://www.nucleodoconhecimento.com.br/engenharia-deproducao/relato-integrado 
Quadro 2 - Checklist de avaliação do Relato Integrado (continua)

\begin{tabular}{|c|c|c|c|c|}
\hline $\begin{array}{l}\text { Estrutura } \\
\text { e } \\
\text { conteúdo } \\
\text { para } \\
\text { elaboração } \\
\text { do } \\
\text { Relatório }\end{array}$ & $\begin{array}{l}\text { Alocação de } \\
\text { recursos e áreas } \\
\text { especiais de } \\
\text { Gestão } \\
\text { (Sustentabilidade } \\
\text { Ambiental) }\end{array}$ & $\begin{array}{l}\text { Apresentar: Critérios de } \\
\text { sustentabilidade nas } \\
\text { contratações } \\
\text { aquisições: Redução de } \\
\text { resíduos poluentes. } \\
\text { Consumo de copos } \\
\text { descartáveis. Ações para } \\
\text { redução do consumo de } \\
\text { recursos naturais. }\end{array}$ & $\mathrm{N}$ & $\begin{array}{l}\text { No RG consta que } 10 \% \text { das } \\
\text { licitações efetuadas no ano de } 2019 \\
\text { foram realizadas sem critérios e } \\
\text { declaração de sustentabilidade. } \\
\text { Nesse RG de } 2019 \text { consta que o } \\
\text { consumo anual de água no ano de } \\
2019 \text { foi maior que os anos de } \\
2017 \text { e } 2018 \text {. Neste mesmo RG de } \\
2019 \text { consta que o consumo de } \\
\text { energia elétrica (fora da ponta) foi } \\
\text { maior que os últimos } 5 \text { anos nos } \\
\text { meses de janeiro, maio, julho, } \\
\text { setembro e novembro. Nesta } \\
\text { mesma página informa que } \\
\text { "haverá, no tocante à iluminação, a } \\
\text { substituição de lâmpadas } \\
\text { fluorescentes por led tubulares". } \\
\text { Logo, a instituição ainda utiliza } \\
\text { lâmpadas fluorescentes, as quais } \\
\text { têm menor eficiência que as de led. } \\
\text { (A barreira encontrada foi a falta } \\
\text { de politica de sustentabilidade para } \\
\text { energia e utilização de água) }\end{array}$ \\
\hline
\end{tabular}

RC: 98639

Disponível em: https://www.nucleodoconhecimento.com.br/engenharia-deproducao/relato-integrado 


\section{Quadro 2 - Checklist de avaliação do Relato Integrado (conclusão)}

\begin{tabular}{|c|c|c|c|c|}
\hline \multirow{4}{*}{$\begin{array}{l}\text { Estrutura } \\
\text { e } \\
\text { conteúdo } \\
\text { para } \\
\text { elaboração } \\
\text { do } \\
\text { Relatório }\end{array}$} & $\begin{array}{l}\text { Informações } \\
\text { orçamentárias, } \\
\text { financeiras e } \\
\text { contábeis }\end{array}$ & $\begin{array}{l}\text { Apresentar quais as principais informações } \\
\text { orçamentárias, financeiras e contábeis, } \\
\text { inclusive de custos, que dão suporte às } \\
\text { informações de desempenho da organização } \\
\text { no período, abrangendo: resumo da situação } \\
\text { financeira contábil da UPC e da evolução no } \\
\text { exercício de referência e em comparação } \\
\text { com o último exercício; principais fatos } \\
\text { contábeis; contas relativas aos fundos de } \\
\text { financiamento com informações sobre o } \\
\text { patrimônio global; conclusões de auditorias } \\
\text { independentes e/ou dos órgãos de controle } \\
\text { público e medidas adotadas em relação a } \\
\text { conclusões ou eventuais apontamentos; } \\
\text { evidenciar a situação e o desempenho } \\
\text { financeiro, orçamentário e patrimonial da } \\
\text { gestão no exercício, deverá haver a } \\
\text { apresentação da declaração do } \\
\text { contador/opinião dos auditores externos, dos } \\
\text { demonstrativos contábeis e das notas } \\
\text { explicativas. }\end{array}$ & $\mathrm{N}$ & $\begin{array}{lr}\text { Neste } & \text { relatório } \\
\text { consta declaração do } \\
\text { contador informando } \\
\text { justificativas } & \text { para } \\
\text { permanência } & \text { de } \\
\text { restrições } & \text { contábeis } \\
\text { no encerramento do } \\
\text { exercício de } & \text { 2019. } \\
\text { (A } & \text { barreira } \\
\text { encontrada foi a falta } \\
\text { de } & \\
\text { contador/profissional } \\
\text { exclusivo r } \\
\text { conformidade } \\
\text { contábil) }\end{array}$ \\
\hline & $\begin{array}{l}\text { Resultados e } \\
\text { Desempenho } \\
\text { da Gestão }\end{array}$ & $\begin{array}{l}\text { Precisa abranger os contratos de gestão, } \\
\text { explicando de que forma seus produtos são } \\
\text { integrados no valor gerado pela unidade e } \\
\text { como contribuem para a eficiência da } \\
\text { gestão. Demonstrar os custos da UPC no } \\
\text { exercício para os principais produtos e } \\
\text { resultados alcançados, evidenciados, } \\
\text { conforme apropriado, por áreas de gestão, } \\
\text { recursos e insumos consumidos. }\end{array}$ & $\mathrm{S}$ & \\
\hline & $\begin{array}{l}\text { Resultados } \\
\text { das principais } \\
\text { áreas de } \\
\text { atuação ou } \\
\text { ações da UPC }\end{array}$ & $\begin{array}{l}\text { As principais áreas e ações devem ter seu } \\
\text { desempenho, em termos de produção e de } \\
\text { conformidade, apresentados em itens } \\
\text { compatíveis, e devem tratar de temas como } \\
\text { os que são exemplificados a seguir: Gestão } \\
\text { orçamentária e financeira, gestão de custos, } \\
\text { gestão de pessoas, gestão de licitações e } \\
\text { contratos, gestão patrimonial e } \\
\text { infraestrutura, gestão da tecnologia da } \\
\text { informação e sustentabilidade ambiental. }\end{array}$ & $\mathrm{S}$ & \\
\hline & $\begin{array}{l}\text { Anexos, } \\
\text { apêndices e } \\
\text { links }\end{array}$ & $\begin{array}{l}\text { Deve proporcionar documentos e } \\
\text { informações úteis à compreensão do } \\
\text { relatório de gestão, especialmente quando } \\
\text { divulgado em versões impressas. }\end{array}$ & S & \\
\hline
\end{tabular}

Fonte: Elaborado pelo autor (2021). 
Após a aplicação do checklist no relatório do ano de 2019 da instituição pesquisada, foi possível identificar as barreiras encontradas na informação deste relatório e as respectivas propostas de mitigação apontadas na literatura.

As 2 barreiras encontradas foram nos elementos:

As 2 barreiras encontradas foram nos elementos:

1. Sustentabilidade ambiental;

2. Informações orçamentárias, financeiras e contábeis.

Após encontradas as barreiras, utilizou-se o framework, alimentado através da pesquisa na literatura, por meio da base SCOPuS, do ano de 2016 ao ano de 2020. Dissertações, artigos e teses no portal da CAPES para a recomendação de boas práticas para mitigação das barreiras. 
Quadro 3 - Framework sobre as boas práticas recomendadas pela literatura (continua).

\begin{tabular}{|c|c|c|}
\hline $\begin{array}{l}\text { TÍTULO DO } \\
\text { TRABALHO } \\
\text { REFERENTE AS } \\
\text { BARREIRAS } \\
\text { ENCONTRADAS }\end{array}$ & $\begin{array}{l}\text { INFORMAÇÕES } \\
\text { COMPLEMENTARES } \\
\text { DE REFERÊNCIA } \\
\text { Fontes: TCU (2020), } \\
\text { autores, dissertações e } \\
\text { teses } \\
\end{array}$ & $\begin{array}{l}\text { (ATIVIDADES/REQUISITOS/PREMISSAS) QUE } \\
\text { ATENDEM AO QUE AS BOAS PRÁTICAS PRESCREVEM }\end{array}$ \\
\hline \multirow{2}{*}{$\begin{array}{l}\text { RELATÓRIO DE } \\
\text { GESTÃO } \\
\text { GUIA PARA } \\
\text { ELABORAÇÃO } \\
\text { NA FORMA DE } \\
\text { RELATÓRIO } \\
\text { INTEGRADO }\end{array}$} & \multirow{2}{*}{$\begin{array}{l}\text { Relatório de gestão: } \\
\text { guia para elaboração } \\
\text { na forma de relato } \\
\text { integrado: evolução da } \\
\text { prestação de contas / } \\
\text { Tribunal de Contas da } \\
\text { União. - 3. ed. - } \\
\text { Brasília: TCU, } \\
\text { Secretaria de Métodos } \\
\text { e Suporte ao Controle } \\
\text { Externo (Semec), } \\
2020 \text {. }\end{array}$} & $\begin{array}{l}\text { O RI precisa ser um documento conciso sobre como a } \\
\text { estratégia, a governança, o desempenho e as perspectivas de } \\
\text { uma organização, no contexto de seu ambiente externo, induz } \\
\text { à geração de valor em curto, médio e longo prazos (Estrutura } \\
\text { Internacional para Relato Integrado, 2013). }\end{array}$ \\
\hline & & $\begin{array}{l}\text { O RI deve ter a consolidação das contas no nível estratégico e } \\
\text { da adoção do relatório integrado, para ficar comprovado os } \\
\text { resultados alcançados. Assim os relatórios ficam bem mais } \\
\text { concisos, por orientarem o relato a partir do modelo de } \\
\text { negócios ou das cadeias de valor das UPCSs e não mais a partir } \\
\text { das atividades de subunidades. }\end{array}$ \\
\hline \multirow{2}{*}{$\begin{array}{l}\text { Relato integrado } \\
\text { no } \\
\text { setor público } \\
\text { brasileiro: } \\
\text { Aplicabilidade e } \\
\text { adaptações }\end{array}$} & \multirow{2}{*}{$\begin{array}{l}\text { Lima, Cintia Zaira } \\
\text { Messias de. (2019), } \\
\text { Coletânea de Pós- } \\
\text { Graduação, v. } 2 \text { n }^{\circ} 3 \\
\text { Auditoria do Setor } \\
\text { Público }\end{array}$} & $\begin{array}{l}\text { O RI deve fornecer uma visão da estratégia da organização, da } \\
\text { vinculação e coerência de sua estratégia com os planejamentos } \\
\text { de médio e de longo prazos do governo federal e de como ela } \\
\text { se relaciona com a capacidade que a organização tem de gerar } \\
\text { valor em curto, médio e longo prazo, também o seu uso e seus } \\
\text { impactos sobre os capitais (IIRC, } 2013, \text { p. } 16 \text { ). }\end{array}$ \\
\hline & & $\begin{array}{l}\text { O RI tem o papel de explicar ao Parlamento e à sociedade em } \\
\text { geral a forma que a organização gera valor público ao longo do } \\
\text { tempo e garante a conformidade da gestão, com destaque para } \\
\text { os avanços e retrocessos do período a que se refere a prestação } \\
\text { de contas (IIRC, 2013, p. } 7 \text { ). }\end{array}$ \\
\hline
\end{tabular}

RC: 98639

Disponível em: https://www.nucleodoconhecimento.com.br/engenharia-deproducao/relato-integrado 


\begin{tabular}{|c|c|c|}
\hline $\begin{array}{l}\text { Governança e } \\
\text { gestão em } \\
\text { aquisições: } \\
\text { proposição de um } \\
\text { modelo para uma } \\
\text { universidade } \\
\text { pública brasileira. }\end{array}$ & $\begin{array}{l}\text { HENNIGEN, Maria. (2018), } \\
\text { Dissertação (Mestrado) - } \\
\text { Curso de Engenharia de } \\
\text { Produção, Programa de Pós- } \\
\text { graduação em Engenharia de } \\
\text { Produção, Universidade } \\
\text { Federal do Rio Grande do Sul, } \\
\text { Poto Alegre }\end{array}$ & $\begin{array}{l}\text { Práticas de governança foram introduzidas e adaptadas } \\
\text { à gestão pública, especialmente pós-Constituição de } \\
1988 \text {, principalmente depois das reformas } \\
\text { administrativas nos anos de } 1990 \text {, inspiradas na } \\
\text { administração pública gerencial, buscando atender ao } \\
\text { principio da efíciência, buscando introduzir os } \\
\text { conceitos de governança, como a compliance, } \\
\text { disclosure e accountability. }\end{array}$ \\
\hline \multirow[b]{2}{*}{$\begin{array}{l}\text { Boas práticas de } \\
\text { Governança } \\
\text { aplicadas ao setor } \\
\text { público: análise na } \\
\text { prestação de } \\
\text { contas de cinco } \\
\text { universidades } \\
\text { públicas federais. }\end{array}$} & \multirow[b]{2}{*}{$\begin{array}{l}\text { CASTRO, Carolina; SILVA, } \\
\text { Guido. v. } 38, \mathrm{n}^{\circ} 17,2017 .\end{array}$} & $\begin{array}{l}\text { O Estado, para se tornar eficiente e atender as } \\
\text { demandas da sociedade por mais transparência, } \\
\text { accountability, equidade e responsabilidade em sua } \\
\text { gestão, é fundamental fortalecer os mecanismos de } \\
\text { governança pública. }\end{array}$ \\
\hline & & $\begin{array}{l}\text { Combater a falta de transparência ou ausência de } \\
\text { mecanismos de controle adequados na avaliação da } \\
\text { prestação de contas das universidades com a } \\
\text { implantação de gestão de riscos e de custos, } \\
\text { planejamento e controle das atividades de auditoria } \\
\text { interna; implantando um código de ética formalizado } \\
\text { pela maior parte da amostra; maior clareza e } \\
\text { transparência nos mecanismos de gestão de pessoas; } \\
\text { inserção da população na tomada de decisão e realizar a } \\
\text { publicação das demonstrações financeiras junto aos } \\
\text { relatórios de gestão, acompanhadas do parecer de } \\
\text { auditoria. }\end{array}$ \\
\hline
\end{tabular}

\begin{tabular}{|c|c|c|}
\hline $\begin{array}{l}\text { Desafios no uso de } \\
\text { metodologias } \\
\text { ágeis de gestão de } \\
\text { projetos em órgãos } \\
\text { públicos: um } \\
\text { estudo de caso da } \\
\text { Receita Estadual } \\
\text { do Paraná. }\end{array}$ & $\begin{array}{l}\text { Oliveira, R. A. de Zych, D. R., } \\
\text { Oliveira, J. de, Michaloski, A. } \\
\text { O. (2020). Revista de Gestão e } \\
\text { Projetos (GeP), 11(2), 12-36 }\end{array}$ & $\begin{array}{l}\text { Combater no setor público a ausência de cultura voltada } \\
\text { à gestão de riscos; estrutura burocrática, rígida e } \\
\text { centralizadora, sem incentivo a processos de inovação; } \\
\text { desconhecimento do tema por seus gestores, através da } \\
\text { capacitação que é um elemento essencial para o sucesso } \\
\text { da implantação da politica de Gestão de Risco. E } \\
\text { necessário ter uma liderança comprometida com o } \\
\text { desenvolvimento de uma cultura de gestão riscos, com a } \\
\text { incorporação da gestão de riscos às responsabilidades } \\
\text { gerenciais, com a implantação de um controle interno } \\
\text { baseado em riscos e com a inserção desta competência } \\
\text { nos programas de formação dos gestores. }\end{array}$ \\
\hline \multirow{2}{*}{$\begin{array}{l}\text { Avaliação da } \\
\text { sustentabilidade } \\
\text { ambiental da sede } \\
\text { administrativa de } \\
\text { uma instituição } \\
\text { federal - Rio de } \\
\text { Janeiro }\end{array}$} & \multirow{2}{*}{$\begin{array}{l}\text { VIEIRA, Igor Laguna; et al., } \\
\text { Brasil Revista Internacional de } \\
\text { Ciências, Rio de Janeiro, v. } 08 \text {, } \\
\mathrm{n}^{\circ} 02 \text {, p. } 168 \text { - } 183 \text {, jul-dez } \\
2018\end{array}$} & $\begin{array}{l}\hat{E} \text { importante que os servidores participem das ações de } \\
\text { uso racional dos recursos naturais e bens públicos, bem } \\
\text { como da gestão adequada dos resíduos sólidos, visto } \\
\text { que tais atividades não devem ficar a cargo de alguns } \\
\text { setores somente, mas devem contar com a participação } \\
\text { de todos. }\end{array}$ \\
\hline & & $\begin{array}{l}\text { É necessário que os órgãos incorporem critérios } \\
\text { sustentáveis em suas compras e contratações de forma } \\
\text { mais efetiva, fazendo seu papel de indutor do mercado } \\
\text { no aumento da oferta de produtos e serviços } \\
\text { sustentáveis. }\end{array}$ \\
\hline
\end{tabular}

Essa proposta de sistemática para implementação de Relato Integrado é composta da junção de três documentos, sendo eles, o diagrama de processos e cheklist, que 
foram elaborados através da análise crítica e reflexiva das normas atuais do TCU e o framework, alimentado através da pesquisa na literatura, por meio da base SCOPuS, do ano de 2016 ao ano de 2020. Dissertações, artigos e teses no portal da CAPES deste mesmo período foram analisados. A partir dos materiais encontrados, foram sintetizadas as boas práticas recomendadas pela literatura para ultrapassar as barreiras encontradas. Esta metodologia servirá de auxílio para a utilização de boas práticas na implementação do Relato Integrado em Instituições de Ensino Superior públicas

\section{CONCLUSÃO}

Nos últimos anos o processo de gestão nas organizações passou a ser encarado como uma ferramenta garantidora de resultados, auxiliando assim os gestores a tomarem as melhores decisões. A transparência da prestação de contas é um instrumento que tem por finalidade avaliar não só as receitas e despesas, mas também a informação não financeira, em especial a nível ambiental, de responsabilidade social e desenvolvimento sustentável, a fim de avaliar e dar suporte à direção desta organização e seus stakeholders.

O objetivo deste estudo foi verificar se existia a presença de barreiras nos relatórios publicados por universidades públicas federais do Brasil. De acordo com os estudos entre o documento do (TCU, 2020) e o Relatório da instituição estudada, foram encontradas 2 barreiras, para as quais as soluções encontradas foram: que a organização tenha seus objetivos estratégicos bem definidos e que haja a avaliação da realização desses objetivos para que possa haver uma mensuração dos resultados alcançados.

Há a necessidade de incorporar nas organizações critérios sustentáveis em suas compras e contratações de forma efetiva, exercendo seu papel de indutor do mercado na ampliação da oferta de produtos e serviços sustentáveis. É importante ainda que todos participem das ações de uso racional dos recursos naturais e bens públicos, bem como da gestão adequada dos resíduos sólidos, já que tais atividades 
não devem ficar a cargo de alguns setores somente, mas precisam contar com a participação de todos.

É necessária mais transparência, accountability, equidade e responsabilidade na gestão, fortalecendo os mecanismos de governança pública. É preciso incluir no programa de formação de gestores a política de Gestão de Risco, buscando obter uma liderança comprometida com o desenvolvimento de uma cultura de gestão de riscos às responsabilidades gerenciais.

Finalmente, deve ser considerada a criação de mecanismos de controle adequados, como gestão de riscos e de custos, planejamento e controle das atividades de auditoria interna na prestação de contas da instituição.

Os resultados desta pesquisa evidenciaram que os Relatórios elaborados pelas organizações do setor público brasileiro possuem barreiras a título de cumprimento das melhores práticas da sustentabilidade, logo, há a necessidade de buscar a melhoria contínua desse processo de mudança e a divulgação das dificuldades encontradas na organização.

\section{REFERÊNCIAS}

BARBIERI, J. C. A educação ambiental e a gestão ambiental em cursos de graduação em administração: objetivos, desafios e propostas. São Paulo: Saraiva, 2004.F

CARVALHO, L. N.; KASSAI, J. R. Nova Revolução Contábil Relato Integrado, v. 1, 2014.

CASTRO, C.; SILVA, G. Boas práticas de Governança aplicadas ao setor público: análise na prestação de contas de cinco universidades públicas federais. Espacios, v. 38, no 17, 2017. Disponível em: <https://dicasliderancagp.com.br/wpcontent/uploads/2018/04/Guia-PMBOK-6\%C2\%AA-Edi\%C3\%A7\%C3\%A3o.pdf>.

Acesso em: 27 maio 2021. 
CERQUEIRA, F. M. M. C. A sustentabilidade nas instituições de Ensino Superior: o caso da Universidade de Coimbra. 2016. Mestrado (Administração Pública Empresarial) - Faculdade de Direito da Universidade de Coimbra. Coimbra, 2016. Disponível em: <http://hdl.handle.net/10316/43196>. Acesso em: 1 fev. 2021.

COLE, L. Assessing sustainability on Canadian university campuses: development of a campus sustainability assessment framework. Dissertação (Mestrado em Meio Ambiente e Gestão) - Royal RoadsUniversity: Victoria, 2003.

Drahein, A. D. Proposta de avaliação de práticas sustentáveis nas operações de serviço em instituições de ensino superior da rede federal de educação profissional, científica e tecnológica. Dissertação (Mestrado em Engenharia de Produção e Sistemas) - Universidade Tecnológica Federal do Paraná. Pato Branco, 2016.

ECCLES, R.G.; KRZUS, M.P. Relatório Único: Divulgação Integrada para uma estratégia sustentável. São Paulo: Saint Paul, 2011.

FOUTO, A. R. F. O papel das universidades rumo ao desenvolvimento sustentável: das relações internacionais às práticas locais. Dissertação (Mestrado em Gestão e Políticas Ambientais Relações Internacionais do Ambiente) - Universidade Nova de Lisboa, 2002.

GÓES, H. C. A. Análise comparativa de instrumentos para avaliação da sustentabilidade em universidades visando uma proposta para o Brasil. Tese (Doutorado em Planejamento Estratégico) - Instituto Alberto Luiz Coimbra de PósGraduação e Pesquisa de Engenharia, Universidade Federal do Rio de Janeiro. Rio de Janeiro: UFRJ, 2015.

GOTTARDO, L. Turismo Sustentável e Desenvolvimento. Estudo de caso "mega resorts" na Costa do Sauípe. Um modelo internacional de desenvolvimento turístico. Dissertação de Mestrado. São Paulo: Unibero, 2002.

GIL, A. C. Como elaborar projetos de pesquisa. São Paulo. Atlas. 1991 
HENNIGEN, M. Governança e gestão em aquisições: proposição de um modelo para uma universidade pública brasileira. Dissertação (Mestrado) - Curso de Engenharia de Produção, Programa de Pós-graduação em Engenharia de Produção, Universidade Federal do Rio Grande do Sul. Porto Alegre, 2018.

IIRC - International Integrated Reporting Council. Capitals background paper for IR. 2013. Disponível em: <http://integratedreporting.org/wp-content/uploads/2013/03/IRBackground-Paper-Capitals.pdf>. Acesso em: 27 maio 2021.

IIRC - Estrutura Internacional para Relato Integrado, 2014. Disponível em: $<$ https://integratedreporting.org/wp-content/uploads/2015/03/13-12-08-THEINTERNATIONAL-IR-FRAMEWORK-Portugese-final-1.pdf>. Acesso em: 21 jan 2021.

LIMA, C. Z. M. Relato Integrado no setor público brasileiro: aplicabilidade e adaptações. Brasília: Tribunal de Contas da União, 2019. Disponível em: $<$ https://portal.tcu.gov.br/biblioteca-digital/relato-integrado-no-setor-publico-brasileiroaplicabilidade-e-adaptacoes.htm>. Acessoem: 5 jun. 2021

Lozano, R. A tool for a graphical assessment of sustainability in universities (GASU). JournalofCleanerProduction, p. 963-72, 2006.

. Métodos e técnicas de pesquisa social. 5.ed. São Paulo: Atlas, 1999.

OLIVEIRA, R. A.; Zych, D. R.; Oliveira, J.; Michaloski, A. O. Desafios no uso de metodologias ágeis de gestão de projetos em órgãos públicos: um estudo de caso da Receita Estadual do Paraná. Revista de Gestão e Projetos (GeP), p. 12-36, 2020. Disponível em: <https://doi.org/10.5585/gep.v11i2.16522>. Acesso em: 22 abr. 2021.

PEREIRA, M. F. Administração estratégica. [Brasília]: CAPES: UAB, 2016. 
RAMÍSIO, P. J. et al. Sustainability Strategy in Higher Education Institutions: Lessons learned from a nine-year case study. Journal of Cleaner Production, v. 222, p. 300309, 2019.

REIS, J. E. A.; SILVA, T. G. ICMS Ecológico e o Princípio da Equidade Intergeracional em prol do Meio Ambiente e da Sociedade - Revista Pensar Acadêmico, v. 15, no 2, p. 211-224, jul./dez. Manhuaçu, 2017.

RIO+20. Documento final da Conferência das Nações Unidas para o Desenvolvimento Sustentável. Rio de Janeiro, 2012.

SANQUETTA, C, R. et al. Emissões de dióxido de carbono associadas ao consumo de energia elétrica no Paraná no período 2010-2014. BIOFIX ScientificJournal, v. 2, no 1, p. 1-6, 2017.

SILVA, G. S.; AZEVEDO, A. L. Indicadores de sustentabilidade para Instituições de Ensino Superior: uma proposta baseada na revisão de literatura. Revista de Gestão Ambiental e Sustentabilidade, v. 8, ํo 1, p.123-144, 2019. Disponível em: <https://www.redalyc.org/articulo.oa?id=471659748008>. Acessoem: 15 de fev. 2021

SHRIBERG, M. Institutional assessment tools for sustainability in higher education: Strengths, weaknesses, and implications for practice and theory. Higher Education Policy, p. 153-167, 2002.

.; SPIESSHOFER, B. Integrated Reporting for a Re-Imagined Capitalism. In BARTON, D., HORVÁTH, D. e KIPPING, M. (orgs.), Re-Imagining Capitalism, Oxford University Press, 2017. Disponível em: $<$ https://www.hbs.edu/faculty/Publication\%20Files/16- $\quad$ 032_3860cfaa-ebd3-4d7eac9a-53272ca8cc2d.pdf>. Acesso em: 27 maio 2021.

STONE, D.; DEADRICK, D. Challenges and opportunities affecting the future of human resource management. HumanResource Management Review, 25, p. 139145. [S.I]: [s.n], 2015.

RC: 98639

Disponível em: https://www.nucleodoconhecimento.com.br/engenharia-deproducao/relato-integrado 
. Tribunal de Contas da União. Decisão normativa-TCU№ 170, de 19 de setembro de 2018.Diário Oficial da União. Brasília: 24 set 2018. Disponível em: $<$ https://www.in.gov.br/materia//asset_publisher/Kujrw0TZC2Mb/content/id/41965540/do1-2018-09-24-decisaonormativa-tcu-n-170-de-19-de-setembro-de-2018-41965175>. Acesso em: 19 fev. 2021.

Tribunal de Contas da União. Decisão normativa-TCU№ 179, de 20 de novembro de 2019.Diário Oficial da União. Brasília: 22 nov 2019. Disponível em: $<$ https://www.in.gov.br/en/web/dou/-/decisao-n-179-de-20-de-novembro-de-2019229118405>. Acesso em: 20 jul. 2021.

- Tribunal de Contas da União. Referencial básico de gestão de riscos. Brasília: TCU, Segecex, 2018. Disponível em: <https://portal.tcu.gov.br/bibliotecadigital/referencial-basico-de-gestao-de-riscos.htm>. Acesso em: 29 maio 2021.

TRIBUNAL DE CONTAS DA UNIÃO. Relatório de gestão: guia para elaboração na forma de relatório integrado: evolução da prestação de contas. 3. ed. Brasília: TCU, Secretaria de Métodos e Suporte ao Controle Externo (Semec), 2020.

Disponível

em: $<$ https://portal.tcu.gov.br/data/files/87/20/39/9D/AA90671053455957F18818A8/Relat orio_gestao_guia_elaboracao_forma_relatorio_integrado_3_edicao.pdf>. Acessoem: 12 fev. 2021.

ULRICH, D.; DULEBOHN, J. Are we there yet? What's next for HR? Human Resource Management Review, 2015.

VIEIRA, I. L.; et al. Avaliação da sustentabilidade ambiental da sede administrativa de uma instituição federal - Rio de Janeiro, Brasil. Revista Internacional de Ciências, v. 08, no 02, p. 168 - 183, jul-dez. Rio de Janeiro, 2018. Disponível em: <http://www.e-publicacoes.uerj.br/ojs/index.php/ric>. Acesso em: 31 jan. 2020.

RC: 98639

Disponível em: https://www.nucleodoconhecimento.com.br/engenharia-deproducao/relato-integrado 
Enviado: Agosto, 2021.

Aprovado: Setembro, 2021. 